\title{
COMMUNICATION
}

Cite this: DOI: 10.1039/xoxxooooox

Accepted ooth January 2012

DOI: $10.1039 /$ xoxxooooox

www.rsc.org/

\section{Direct evidence of Lowenstein's rule violation in swelling high-charge micas}

\author{
E. Pavón, ${ }^{a}$ F. J. Osuna, ${ }^{b}$ M. D. Alba ${ }^{b}$ and L. Delevoye ${ }^{a}$
}

The structure of high-charged micas, Na-n-mica ( $n=2$ and 4), a family of synthetic silicates with wide range of applications, was investigated by use of ${ }^{17} \mathrm{O}$ solid-state $\mathrm{NMR}$ at natural abundance in order to preserve quantitative spectral information. The use of very high-field and highly sensitive probehead, together with ${ }^{17} \mathrm{O}$ NMR literature data allowed for detection of isolated signal at $26 \mathrm{ppm}$ to be assigned partially to AlOAl, as evidence of the violation of the Lowenstein's rule for $\mathrm{Na}-4-m i c a$.

Swelling high-charged micas are a new family of the synthesized silicates with important applications in contaminant removal $^{1}$ and acid catalyst. ${ }^{2}$ Their properties depend on both total layer charge and the active center distribution on the framework. ${ }^{3}$ However, some major challenges about aluminum (as active center) distribution still needs to be addressed. For example, Na-4-mica exhibit a $\mathrm{Si} / \mathrm{Al}$ ratio equal to one and according to Lowenstein's rule, only one $\mathrm{Si}$ environment, namely $\mathrm{Si}(3 \mathrm{Al})$, should be observed. However, Alba et al. ${ }^{3 \mathrm{a}}$ observed, using ${ }^{29} \mathrm{Si}$ MAS NMR, up to five different silicon environments which can be interpreted either by a violation of Lowenstein's rule or by a $\mathrm{Si} / \mathrm{Al}$ ratio lower than 1 . Other authors, who reported a need for clarity, made similar observations and interpretations. ${ }^{4}$ Solid-state MAS NMR is a powerful technique to probe the local structure of those systems for which X-ray diffraction methods fail in distinguishing between $\mathrm{Al}$ and $\mathrm{Si}$ atoms as well as in giving the protons' position. For example, ${ }^{27} \mathrm{Al}$ MAS NMR provides unambiguous access to the aluminum coordination as tetra-, penta- and hexacoordinated Al environments are found in clear distinct chemical shift range. ${ }^{5}$ In mica systems, though, ${ }^{27} \mathrm{Al}$ MAS
NMR fails to bring distinction in the Al chemical environment within a coordination type due to the large distribution of NMR parameters that dominates the spectral feature. ${ }^{3 \mathrm{a}}$
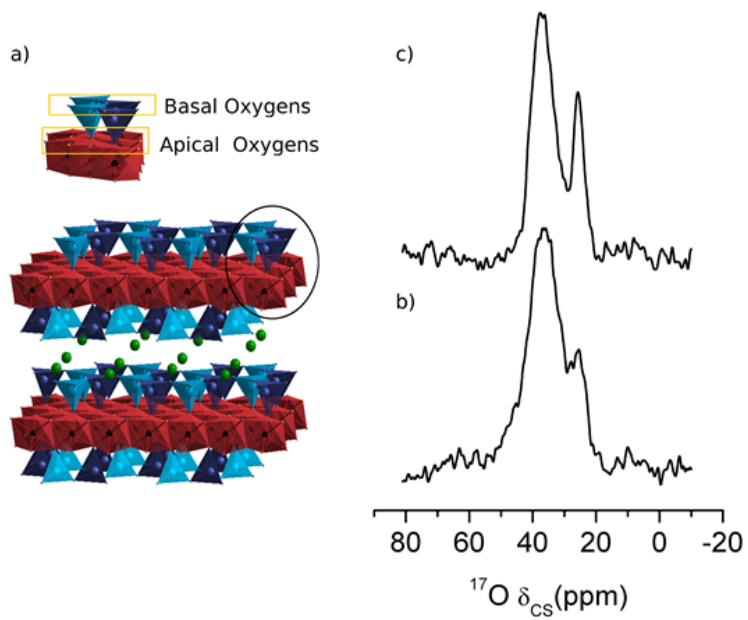

Figure 1. a) Mica structure for which dark and light blue tetrahedra represent the $\mathrm{Si}$ and $\mathrm{Al}$ tetrahedral environments, respectively; red octahedra represent octahedral $\mathrm{Mg}$ and green circles correspond to the interlayer $\mathrm{Na}$. In the upper figure, basal and apical oxygens are displayed. b) Na-2-Mica and c) Na-4-Mica ${ }^{17} \mathrm{O}$ NMR spectra recorded at $800 \mathrm{MHz}$ at natural abundance.

For the last decade, many MAS NMR studies have involved oxygen-17, an NMR-active nucleus with informative parameters that can be related directly to the local structure. Indeed, ${ }^{17} \mathrm{O}$ chemical shift values $\left(\delta_{\mathrm{CS}}\right)$ and quadrupolar coupling constants $\left(\mathrm{C}_{\mathrm{Q}}\right)$ depend upon the identity, the number and the distance to nearest-neighbor atoms and are spread over 
a large range $\left(>1000 \mathrm{ppm}\right.$ for $\left.\delta_{\mathrm{CS}}\right) .{ }^{6}$ However, due to its low natural abundance $(0.034 \%)$, solid-state NMR studies have often required prior isotopic enrichment which is laborious, expensive, and homogeneity of enrichment is often not ensured. More recently, Blanc et al. ${ }^{7}$ have used electron spin transfer using Dynamic Nuclear Polarization (DNP) to enhance the ${ }^{17} \mathrm{O}$ NMR signal of a series of model compounds at ${ }^{17} \mathrm{O}$ natural abundance. Unfortunately, DNP enhancing method is difficult to adapt to low porosity materials, such as micas, without affecting the structure, since the source of electron is obtained through the impregnation of a radical agent. ${ }^{8}$

The aim of the present communication is to show that natural abundance ${ }^{17} \mathrm{O}$ MAS NMR at very high magnetic field (18.8T) brings unambiguous and direct evidence of Lowenstein's rule compliance or violation in Na-n-mica systems. We have selected two synthetic Na-n-mica $(n=2$ and 4). They are swelling and highly-charged sodium fluorophlogopites, 2:1 phyllosilicates with $\mathrm{Mg}$ in the octahedral sheet and a high charge density due to isomorphic substitution of $\mathrm{Al}^{3+}$ for $\mathrm{Si}^{4+}$ in tetrahedral sheet. ${ }^{9}$ These 2:1 phyllosilicates are made from the combination of two basic building blocks: a sheet of edgesharing $\left[\mathrm{MO}_{4}\right]$ units, $\mathrm{M}=\mathrm{Si}$ or $\mathrm{Al}$, (the tetrahedral sheet) and another one of edge-sharing $\left[\mathrm{MgO}_{4} \mathrm{~F}_{2}\right]$ (the octahedral sheet) (Figure 1a). The Si or Al tetrahedra share three of the four oxygens with other tetrahedra and form a rough hexagonal honeycomb in the basal plane. The fourth oxygen of the $\left[\mathrm{MO}_{4}\right]$ units, named apical oxygen, is shared with the octahedral sheet. Consequently, up to five oxygen environments can be encountered. The basal oxygens can be found in the following environments, SiOSi, SiOAl or AlOAl, whereas the apical oxygens are either $\mathrm{SiOMg}$ or AlOMg environments.

Table 1. Framework environment distribution in Na-n-mica with Lowenstein's rule compliance (model I) and with Lowenstein's rule violation (model II).

\begin{tabular}{|c|c|c|c|c|c|c|}
\hline \multirow[t]{3}{*}{ Model } & \multirow[t]{3}{*}{$\mathrm{n}$} & \multicolumn{5}{|c|}{$\%$ Oxygen sites } \\
\hline & & \multicolumn{3}{|c|}{ Basal Oxygens } & \multicolumn{2}{|c|}{ Apical Oxygens } \\
\hline & & $\mathrm{SiOSi}$ & $\mathrm{SiOAl}^{\text {tet }}$ & $\mathrm{Al}^{\text {tet }} \mathrm{OAl}^{\text {tet }}$ & $\mathrm{SiOMg}$ & $\mathrm{AlOMg}$ \\
\hline \multirow{2}{*}{ I } & 2 & 48.30 & 26.00 & - & 18.75 & 6.25 \\
\hline & 4 & - & 75.00 & - & 12.50 & 12.50 \\
\hline II & 4 & 13.94 & 47.75 & 11.25 & 12.50 & 12.50 \\
\hline
\end{tabular}

The ${ }^{17}$ O MAS NMR spectra ${ }^{\dagger}$ of Na-n-mica ( $n=2$ and 4) (Fig. 1b and c) show signal in two well-defined chemical shift regions. The main region is spread from 30 to $50 \mathrm{ppm}$ and the second one between 20 and $30 \mathrm{ppm}$. Many authors have carried out ${ }^{17} \mathrm{O}$ MAS NMR experiments on series of ${ }^{17} \mathrm{O}$ enriched aluminosilicates and the main NMR parameters $\left(\delta_{C S}\right.$ and $\left.C_{Q}\right)$ are summarized in Figure 2. Two well-defined chemical shift regions are observed. Region A is spread from 30 to $55 \mathrm{ppm}$ and corresponds to $\mathrm{SiOSi}$ and $\mathrm{SiOAl}{ }^{\text {tet }}$. The only way to distinguish between these two environments is by referring to the $\mathrm{C}_{\mathrm{Q}}$ value, which is larger for Si-O-Si sites $\left(4<\mathrm{C}_{\mathrm{Q}}<6 \mathrm{MHz}\right)$ than for $\mathrm{Si}-\mathrm{O}-\mathrm{Al}^{\text {tet }}$ sites $\left(2.5<\mathrm{C}_{\mathrm{Q}}<3 \mathrm{MHz}\right)$. Region $\mathrm{B}$ is spread from 15 to $30 \mathrm{ppm}$ and corresponds to $\mathrm{Al}^{\text {tet }} \mathrm{OAl}^{\text {tet }}$ sites, only found in aluminosilicates.
To the best of our knowledge, there is no literature evidence for SiOMg and AlOMg ${ }^{17} \mathrm{O}$ NMR studies and thus, no well-defined chemical shift ranges can be found. In order to interpret our ${ }^{17} \mathrm{O}$ NMR experimental data, we hence identified the different possible environments taking into account two models (Table 1). Model I is based on the compliance to the Lowenstein's rule and therefore, the coordination of basal oxygens by two aluminium, $\mathrm{Al}^{\text {tet }} \mathrm{OAl}^{\text {tet }}$, is forbidden. The statistical distribution of the other four environments depends on the layer charge (Table 1) and, in the case of Na-4-mica, only $\mathrm{SiOAl}^{\text {tet }}$ in tetrahedral sheet is possible. Model II is based on the violation of the Lowenstein's rule. In such a case, for basal oxygens, three environments are possible for $\mathrm{Si} / \mathrm{Al}=1, \mathrm{Na}-4-$ mica, instead of only one environment observed with Model I. The Lowenstein's rule can violated to varying degree and in this case we have assumed a $15 \%$ of $\mathrm{Al}-\mathrm{O}-\mathrm{Al}$ from the ${ }^{29} \mathrm{Si}$ MAS NMR data. ${ }^{3}$

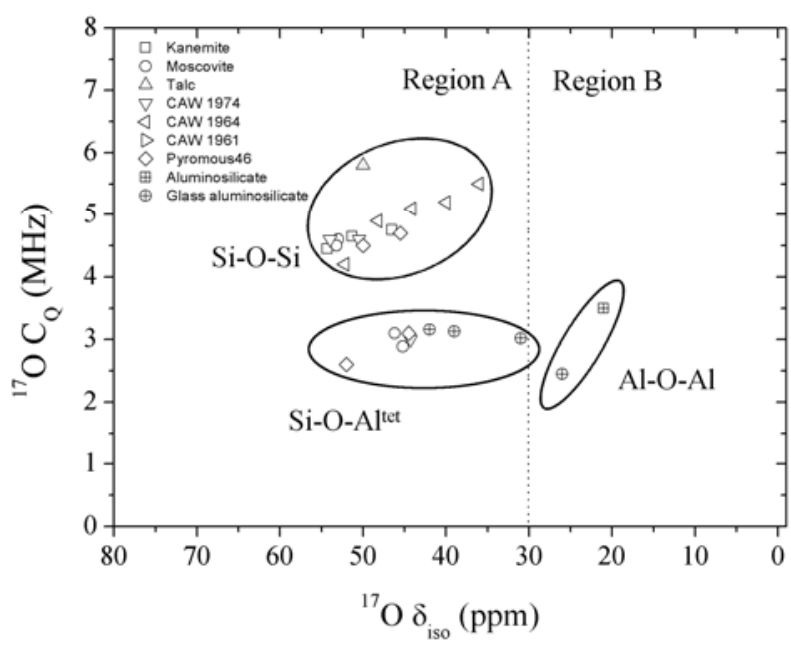

Figure 2. ${ }^{17} \mathrm{O}$ experimental $\mathrm{C}_{\mathrm{Q}}$ and $\delta_{\text {iso }}$ of oxygen sites in layer silicates. Squares and circles are used to illustrate Kaolinite and Muscovite respectively ${ }^{10}$ whereas up triangle is for Talc ${ }^{11}$. Down, left and right triangles are for samples called CAW 1974 (kaolinite + smectite, Al/Si =2), CAW 1964 and CAW 1961 (both are a mixture of Pyrophyllite and kaolinite, with an $\mathrm{Al} / \mathrm{Si}$ ratio equal to 1$).{ }^{12}$ Diamonds are for Pyromous $46^{13}$ (a mixture kaolinite + montmorillonite). Crossed circles and squares are two types of aluminosilicate glasses. ${ }^{14}$

Considering the chemical shift distribution from Figure 2, it is clear that the most intense signal in the ${ }^{17} \mathrm{O}$ MAS NMR spectra of both micas is due to the overlapping of at least two contributions, $\mathrm{SiOSi}$ and $\mathrm{SiOAl}^{\text {tet }}$. However, the assignment of the lower chemical shift signal depends on the Lowenstein's rule compliance. If Lowenstein's rule is obeyed, the NMR signal at low chemical shift does not result from $\mathrm{Al}^{\text {tet }} \mathrm{OAl}^{\text {tet }}$ environments and must be due to contributions from $\mathrm{SiOMg}$ and/or AlOMg. If both apical oxygen environments contribute to this signal, equal relative intensities of this signal must be expected for both micas (Table 1). Since this signal is almost double in the case of Na-4-mica, only one of them, SiOMg or $\mathrm{AlOMg}$, must be the responsible of this resonance. The integration of both regions is possible for ${ }^{17} \mathrm{O}$ MAS NMR 
spectrum of Na-4-mica due to the small overlapping of the signals. We found that the resonance centred at $26 \mathrm{ppm}$ accounts for about $25 \%$ of the total signal, which exceeds the contribution from one of the two apical oxygens and $\mathrm{Al}^{\text {tet }} \mathrm{OAl}^{\text {tet }}$ environment must also be contributing to this signal (Table 1). Therefore, the ${ }^{17} \mathrm{O}$ MAS NMR spectrum of Na-4-mica (Figure 1c) indicates that the Lowenstein's rule is not followed, validating model II.

Further considerations based on electronegativity may also shed a light into the chemical shift region of both apical oxygen environments. Based on simple quantum chemical calculations that take into account the paramagnetic contribution of the chemical shift, ${ }^{15}$ the ${ }^{29} \mathrm{Si}$ chemical shift becomes more shielded as the cation electronegativity (EN) increases. ${ }^{16}$ Figure 2 demonstrates that the substitution of two $\mathrm{Si}(\mathrm{EN}(\mathrm{Si})=1.90)$ by two $\mathrm{Al}(\mathrm{EN}(\mathrm{Al})=1.61)^{16}$ shift the signal to lower chemical shifts by about $20 \mathrm{ppm}$, in good agreement with what is observed for other nuclei. ${ }^{17,18}$ Schrämm and Oldfield ${ }^{19}$ found that the ${ }^{17} \mathrm{O}$ NMR signal shifts to lower chemical shifts as the ionic radii increases, therefore, the substitution of $\mathrm{Si}^{4+}(\mathrm{r}=0.40 \AA)$ by $\mathrm{Al}^{3+}$ $(\mathrm{r}=0.53 \AA)$ should cause a lower frequency shifts of the NMR signal. By extrapolation, the ${ }^{17} \mathrm{O}$ of the $\mathrm{SiOMg}$ environment must give a resonance at higher chemical shift $(>30 \mathrm{ppm})$ than AlOMg. The signal centered at $26 \mathrm{ppm}$ in Na-4-mica thus results from the overlapping of $\mathrm{AlOMg}$ and $\mathrm{Al}^{\text {tet }} \mathrm{OAl}^{\text {tet }}$ environments.

\section{Conclusions}

This communication provides the first direct evidence of Lowenstein's rule violation in swelling high-charged micas, based on natural abundant ${ }^{17} \mathrm{O}$ MAS NMR and avoiding the problem of inhomogeneous enrichment. The confirmation of the present assignment together with a precise fitting of the ${ }^{17} \mathrm{O}$ NMR spectrum is underway by additional use of recent DFT method that can be used to calculate NMR parameters.

\section{Notes and references}

${ }^{a}$ Unité de Catalyse et de Chimie du Solide, UCCS CNRS, UMR8181, Université Lille Nord de France, 59655 Villeneuve d'Ascq (France), Email: laurent.delevoye@ensc-lille.fr. Tel.: +33 320-335-907

${ }^{b}$ Instituto Ciencia de los Materiales de Sevilla (CSIC-US). Avda. Americo Vespucio, 49. 41092-Sevilla (Spain).

$\dagger$ Electronic Supplementary Information (ESI) available: Synthesis and NMR experimental procedures. See DOI: 10.1039/c000000x/

Acknowledgements: We thank the CNRS, the French Ministry of Higher Education and Research, the TGIR-RMN-THC Fr3050 CNRS, the Excellence Project FQM 567 from Andalusian government for their financial support. We want to specifically acknowledge Peter Gorkov, for the development of the $4 \mathrm{~mm}$ HX probehead.

1 T. Kodama, Y. Harada, M. Ueda, K. Shimuzo, K. Shuto and S. Komarneni, Langmuir 2001, 17, 4881.

2 A.C. Perdigón, D. Li, C. Pesquera, F. González, B. Ortiz, F. Aguado, and C. Blanco, Journal of Materials Chemistry A, 2013, 4, 1213.
3 a) M.D. Alba, M.A. Castro, M. Naranjo and E. Pavon, Chemistry of Materials, 2006, 18, 2867; b) M. D. Alba, A. I. Becerro, M. A. Castro and A. C. Perdigón, American Mineralogy, 2001, 86, 124.

4 Y. D. Noh, S. Komarneni, K.J.D. Mackenzie, H. M. Ro and M. Park, Separation and Purification Technology, 2013, 104, 238.

5 a) J. Sanz and J. M. Serratosa, Journal of the American Chemical Society, 1984, 106, 4790; b) L. B. Alemany and G. W. Kirker, Journal of the American Chemical Society, 1986, 108, 6158.

6 a) I.P. Gerothanassis, Progress in Nuclear Magnetic Resonance Spectroscopy, 2010, 56, 95; b) I.P. Gerothanassis Progress in Nuclear Magnetic Resonance Spectroscopy 2010, 57, 1.

7 F. Blanc, L. Sperrin, D.A. Jefferson, S. Pawsey, M. Rosay and C.P. Grey, Journal of the American Chemical Society 2013, 135, 2975.

8 C. Sauvée, M. Rosay, G. Casano, F. Aussenac, R. T. Weber, O. Ouari and P. Tordo, Angewandte Chemie, International Edition, 2013, 52, 10858.

9 a) M. Park, D.H. Lee, C.L. Choi, S.S. Kim, K.S. Kim and J. Choi, Chemistry of Materials, 2002, 14, 2582; b) K. Shimizu, K. Hasegawa, Y. Nakamuro, T. Kodama and S. Komarneni, Journal of Materials Chemistry, 2004, 14, 1031.

10 S.K. Lee and J.F. Stebbins, American Mineralogy, 2003, 88, 493.

11 T.H. Walter, G. L. Turner and E. Oldfield, Journal of Magnetic Resonance, 1988, 76, 106.

12 S.K. Lee, J. Stebbins, C. A. Weiss Jr. and R. J. Kirkpatrick, Chemistry of Materials, 2003, 15, 2605.

13 S. K. Lee and C. A. Weiss Jr. American Mineralogy, 2008, 93, 1066.

14 E. Yildirim and R. Dupree, Bulletin of Materials Science, 2004, 27, 269.

15 G. Engelhardt and R. Radeglia, Chemical Physics Letters, 1984, 108, 271.

16 C.A. Weiss Jr., S. P. Altaner and R. J. Kirkpatrick, American Mineralogy, 1987,72, 935.

17 L. Pauling, The Nature of the Chemical Bond, Cornell Univ., USA, 3rd ed., 1960

18 S.E. Ashbrook and M.E. Smith, Chemical Society Review, 2006, 35, 718-735.

19 S. Schrämm and E. Oldfield, Journal of the American Chemical Society, 1984, 106, 2502-2506. 